\title{
Uso da fibrina rica em plaquetas na estética e rejuvenescimento facial: Revisão integrativa
}

\author{
Use of platelet-rich fibrin in aesthetics and facial rejuvenation: Integrative review \\ Uso de fibrina rica en plaquetas en estética y rejuvenecimiento facial: Revisión integrativa
}

Recebido: 29/06/2021 | Revisado: 05/07/2021 | Aceito: 14/07/2021 | Publicado: 24/07/2021

Lyles Regina Machado Falcão

ORCID: https://orcid.org/ 0000-0001-5782-8827

Universidade Federal de Alagoas, Brasil

E-mail: falcaolyles@gmail.com

Stela Maris Wanderley Rocha

ORCID: https://orcid.org/0000-0002-3220-648X Universidade Federal de Alagoas, Brasil

E-mail: stelawanderley@hotmail.com

Kelly Rodrigues Mota

ORCID: https://orcid.org/0000-0002-1656-608X Universidade Federal de Alagoas, Brasil

E-mail: kellyrmota@outlook.com

Taianne Aída Joia Malta

ORCID: https://orcid.org/0000-0002-2031-466X Centro de Estudos Superiores de Maceió, Brasil

E-mail: maltataianne@gmail.com

Roberta Albuquerque Acioli Rios

ORCID: https://orcid.org/0000-0002-8506-653X

Centro de Estudos Superiores de Maceió, Brasil

E-mail: betarios@globo.com

Katharina Jucá de Moraes Fernandes

ORCID: https://orcid.org/0000-0003-0002-3133

Centro de Estudos Superiores de Maceió, Brasil

E-mail: katharina.fernandes@cesmac.edu.br

João Francisco Tenório Neto

ORCID: https://orcid.org/0000-0002-5094-4566

Centro de Estudos Superiores de Maceió, Brasil

E-mail: joaotenorioperio@gmail.com

Rômulo Savage Vanderlan do Nascimento

ORCID: https://orcid.org/0000-0001-9436-7679

Universidade Mario Pontes de Jucá, Brasil

E-mail: romulovanderlan@gmail.com

\begin{abstract}
Resumo
A fibrina rica em plaquetas (PRF) é considerada um biomaterial de preenchimento, empregado atualmente tanto na área médica quanto odontológica. Este trabalho tem por objetivo avaliar a utilização de PRF em procedimentos estéticos e se o seu uso possui ação rejuvenescedora na face. O estudo utiliza os termos "Fibrina rica em plaquetas","Rejuvenescimento facial", "Engenharia tecidual" e "Odontologia cosmética" para refinamento da busca nas bases de dados: PUBMED, MEDLINE e LILACS, entre o início do ano de 2016 a março de 2021. Os critérios para inclusão dos artigos foram a utilização do PRF em casos de estudo e ensaios clínicos no rejuvenescimento da face. Os critérios de exclusão eliminaram estudos repetidos, que adotaram um delineamento diferente do supracitado, ou, que abordasse uma terapêutica utilizando o PRF que não fosse na face. Verificou-se com a busca 6 estudos experimentais ou observacionais considerados elegíveis, que foram incluídos na síntese qualitativa. Os trabalhos incluídos mostraram que não há padronização quanto ao preparo do PRF, havendo diferentes protocolos de aplicação desse biomaterial, e, que embora os autores tenham obtido êxito e observado melhora com relação ao aspecto da pele, há risco "alto" ou "indefinido" de viés favorecendo resultados positivos. Concluiu-se que o PRF é um material seguro e tem resultado sobre a melhora do aspecto da pele, sendo necessário estudos futuros que analisem o seu efeito a longo prazo.

Palavras-chave: Fibrina rica em plaquetas; Rejuvenescimento facial; Engenharia tecidual; Odontologia cosmética.
\end{abstract}

\section{Abstract}

Platelet-rich fibrin (PRF) is considered a filler biomaterial, currently used in both the medical and dental fields. This work aims to evaluate the use of PRF in aesthetic procedures and whether its use has rejuvenating action on the face. The study uses the terms "Platelet-rich fibrin", "Facial rejuvenation", "Tissue engineering" and "Cosmetic dentistry" to 
refine the search in the databases: PUBMED, MEDLINE and LILACS, between the beginning of the year 2016 to March of 2021. The criteria for inclusion of the articles were the use of the PRF in case studies and clinical trials in face rejuvenation. The exclusion criteria eliminated repeated studies that adopted a different design from the one mentioned above, or that addressed a therapy using the PRF that was not on the face. The search revealed experimental or observational studies considered eligible, which were included in the qualitative synthesis. The studies included showed that there is no standardization regarding the preparation of the PRF, with different application protocols for this biomaterial, and that although the authors were successful and observed improvement in relation to the appearance of the skin, there is a "high" or "undefined" risk bias favoring positive results. It was concluded that PRF is a safe material and has improved the appearance of the skin, requiring further studies to analyze its long-term effect.

Keywords: Platelet-rich fibrin; Facial rejuvenation; Tissue engineering; Cosmetic dentistry.

\section{Resumen}

La fibrina rica en plaquetas (PRF) se considera un biomaterial de relleno y se utiliza actualmente tanto en el campo médico como dental. Este estudio tiene como objetivo evaluar el uso de PRF en procedimientos estéticos y si su uso tiene una acción rejuvenecedora en el rostro. El estudio utiliza los términos "Fibrina rica en plaquetas", "Rejuvenecimiento facial", "Ingeniería de tejidos" y "Odontología cosmética" para afinar la búsqueda en las bases de datos: PUBMED, MEDLINE y LILACS, entre principios del año 2016 y marzo de 2021. Los criterios para la inclusión de los artículos fueron el uso del PRF en estudios de casos y ensayos clínicos en el rejuvenecimiento del rostro. Los criterios de exclusión eliminaron estudios repetidos que adoptaron un diseño diferente al mencionado anteriormente, o que abordaron una terapia con PRF que no estaba en la cara. La búsqueda reveló 6 estudios experimentales u observacionales considerados elegibles, que fueron incluidos en la síntesis cualitativa. Los estudios incluidos mostraron que no existe una estandarización en cuanto a la preparación del PRF, con diferentes protocolos de aplicación para este biomaterial, y que si bien los autores tuvieron éxito y observaron mejoría en relación al aspecto de la piel, existe un "alto" o Sesgo de riesgo "indefinido" que favorece los resultados positivos. Se concluyó que el PRF es un material seguro y ha mejorado la apariencia de la piel, requiriendo más estudios para analizar su efecto a largo plazo.

Palabras clave: Fibrina rica en plaquetas; Rejuvenecimiento facial; Ingeniería de tejidos; Odontología cosmética.

\section{Introdução}

A busca por meios de acelerar a cicatrização e o reparo tecidual é um assunto de interesse da área odontológica e da medicina regenerativa (Bielecki \& Dohan Ehrenfest, 2012). A evolução nas técnicas de reparo tecidual utilizando concentrados sanguíneos advém do final da década de 1990, com a divulgação dos primeiros concentrados de plasma denominados "PRP” (Platelet-rich plasma) (Marx et al., 1998) e "PDGF" (Platelet-Derived Growth Factor) (Anitua, 1999), na área de cirurgia oral e maxilofacial (Mihaylova et al., 2017; Whitmann, Berry \& Green, 1997). Em seguida surgiu a segunda geração de agregados plaquetários, conhecida como PRF (Platelet-rich fibrin) no ano de 2000 (Choukroun, Adda, Schoeffler \& Vervelle, 2001), até a chegada do recente coágulo avançado de fibrina, ou, A-PRF (Advanced PRF), em 2014 (Ghanaati et al., 2014; El Bagdadi et al., 2017; Wang, Zhang, Choukroun, Ghanaati \& Miron, 2017).

Diferentemente dos concentrados sanguíneos de primeira geração, que eram obtidos através de um processo mais longo e dispendioso, o PRF é obtido através de um protocolo simples no qual o sangue é coletado em tubos secos de vidro ou de plástico, e, submetido a uma única centrifugação suave, sem adição de anticoagulantes. Seu preparo utiliza menos tempo clínico e oferece mais vantagens com relação ao reparo tecidual devido a estrutura tridimensional do coágulo de fibrina, tendo, portanto, um efeito mais duradouro nas regiões de aplicação e uma melhor resposta celular (Dohan Ehrenfest, Del Corso, Mouhyi \& Charrier, 2017).

A resolução do conselho federal de odontologia ${ }^{\circ}$ 158, de 08 de junho de 2015 regulamenta o uso de PRP e PRF para fins não transfusionais no âmbito da odontologia, desde que o profissional seja habilitado, tenha infraestrutura, insumos e meios adequados para realização da técnica (Conselho Federal de Odontologia, 2015), e, desde então, o PRF tem servido a uma variedade de procedimentos cirúrgicos e não cirúrgicos ao cirurgião-dentista(Ghanaati et al., 2014; El Bagdadi et al., 2017; Choukroun, 2017).

Uma das vantagens do PRF é que ele pode fornecer por mais tempo células favoráveis a regeneração aos tecidos hospedeiros, sem temer uma reação de corpo estranho, devido a sua origem autóloga (Choukroun, 2017) e à presença de elementos sanguíneos 
como: plaquetas, células derivadas dos megacariócitos, anucleadas, que são uma fonte natural de fatores de crescimento (Nurden, Nurden, Sanchez, Andia \& Anitua, 2017).

O PRF é considerado um adjuvante cirúrgico, cumprindo a função de reproduzir dois fenômenos naturais: a coagulação sanguínea e o reparo tecidual (Bielecki \& Dohan Ehrenfest, 2012). A diferença entre o sangue natural e o PRF, é que o último é mais homogêneo, estável e passível de associação com outros materiais para aplicação. Assim, o PRF não deve ser considerado um simples reforço anti-hemorrágico, e sim um composto sólido, adaptativo e polimórfico que leva a uma rápida estruturação de novos tecidos (Mihaylova et al., 2017; Wang, Zhang, Choukroun, Ghanaati \& Miron, 2017).

Com o conhecimento sobre suas propriedades no meio científico, o uso de PRF passou a ser indicado para uma variedade de procedimentos estéticos que se concentram em melhorar a aparência e diminuir os sinais da idade, se destacando pela praticidade (Lin \& Sclafani, 2018), segurança (Nacopoulos \& Vesala, 2020; Wei et al., 2017; Liang et al., 2018) e recuperação mais regular, obtendo melhores resultados quando comparado a materiais sintéticos (Storrer et al., 2019).

Embora algumas dificuldades tenham sido relatadas em relação ao uso do PRF, como a falta de padronização no seu preparo e, consequentemente, a dificuldade de comparar e indicar o protocolo mais indicado para cada caso (Gentile, 2020), há estudos divulgados relatando resultados promissores a partir do seu uso na diminuição de manchas, poros, rugas, porfirinas, e melhora no aspecto desses e outros sinais de envelhecimento (Nacopoulos \& Vesala, 2020; Karimi \& Rockwell, 2019). O envelhecimento da pele é um processo inevitável, influenciado por fatores genéticos, ambientais, exposição ao sol, e poluição, que causam danos ao DNA e consequentemente provocam uma série de alterações físicas na pele, incluindo atrofia, telangiectasia, rugas finas e profundas, elastose solar, e despigmentação. Outros fatores como má alimentação, falta de exercício, consumo de cafeína e drogas também são conhecidos por acelerarem o processo de envelhecimento (Choukroun, 2017; Nacopoulos \& Vesala, 2020).

A ablação em tecidos moles da face ocasionado pela idade pode evidenciar demarcações cutâneas óbvias, como: sulcos, cantos da boca, bochechas, pálpebras, testa, sobrancelha e nariz. Com base nessas alterações, existe uma variedade de procedimentos estéticos, cirúrgicos ou minimamente invasivos, que podem ser realizados a fim de favorecer uma melhora na aparência da pele ou prevenir o envelhecimento precoce (Nacopoulos \& Vesala, 2020; Karimi \& Rockwell, 2019; Hassan, Quinlan \& Ghanem, 2020).

Entretanto, desde o primeiro relato de seu uso, há cerca de vinte anos, como adjuvante cirúrgico em terapêuticas regenerativas in situ (Kubesch et al., 2019; Simonpieri et al., 2012), notou-se que o material tem sido descrito com maior frequência nas cirurgias orais e maxilo-faciais e na implantodontia na área odontológica, o que leva a crer que esses achados ocorrem porque, inicialmente, ele foi desenvolvido para reparo em tecidos duros e moles e recentemente ele vem sendo utilizado também pela área estética no rejuvenescimento facial, portanto, as baixas evidências caracterizam uma janela científica a cerca do tema.

\section{Materiais e Métodos}

Este trabalho se trata de uma revisão integrativa, onde buscou-se possibilitar uma síntese do conhecimento científico a cerca do tema investigado. O propósito desse método é sistematizar e consolidar uma determinada hipótese ou fenômeno, considerando como fonte estudos primários já realizados que forneçam dados qualitativos de diferentes naturezas sobre o assunto, baseando-se nas seguintes etapas: elaboração da pergunta norteadora, busca ou amostragem na literatura, coleta de dados, análise crítica dos estudos incluídos, discussão dos resultados, e formulação da revisão integrativa (Souza, Silva \& Carvalho, 2010).

Uma estratégia de busca foi desenvolvida adotando o PUBMED, MEDLINE e LILACS como bases de dados e utilizando as palavras-chave (Termos MeSH e/ou palavras-termo) "Fibrina rica em plaquetas" combinada em pares e em trios 
com as outras palavras-termo e/ou MeSH: "Rejuvenescimento facial", "Engenharia tecidual" e "Odontologia cosmética" por meio de operadores booleanos "E" e/ou "OU".

Apenas estudos publicados entre janeiro de 2016 a março de 2021, escritos em inglês, e que possuíssem delineamento experimental (séries de casos, estudos prospectivos, ensaios clínicos controlados, randomizados ou não), e observacional (estudos de caso-controle e estudos de coorte) realizados in vivo foram considerados elegíveis para esse estudo. Para sua inclusão, os artigos precisavam abordar sobre o uso do PRF no rejuvenescimento facial e qual o resultado dos estudos em que houve aplicação desse material com fins estéticos na face.

Inicialmente, os artigos foram analisados segundo título, e aqueles que não correspondiam ao tema ou estavam duplicados foram excluídos. Artigos elegíveis foram avaliados através do seu resumo, e em seguida, os que correspondiam aos critérios de inclusão foram lidos na íntegra. Após serem avaliados, restaram apenas aqueles que atendiam a todos os critérios. Para o estudo, os dados dos artigos incluídos foram extraídos e organizados em tabelas de modo a sintetizar os principais detalhes: base de dados, título, autores/ano, delineamento/amostra, objetivos, país, periódico, método/dose, $\mathrm{n}^{\mathrm{o}}$ de sessões/intervalo, seguimento, centrifugação/preparo e conclusões relevantes para o estudo.

\section{Resultados}

A amostra final desta revisão foi constituída por seis artigos científicos na língua inglesa, selecionados pelos critérios de inclusão previamente estabelecidos. Destes, todos os seis foram encontrados na base de dados PUBMED. O Quadro 2 e 3 representa as especificações de cada um dos artigos.

A pesquisa exploratória encontrou 704 artigos potencialmente elegíveis. Após avaliação por título e exclusão das duplicatas, restaram 22 artigos para serem analisados pela leitura dos resumos (Figura 1). Destes, 8 artigos não atenderam ao objetivo desse estudo, e 14 estudos completos foram avaliados para elegibilidade e foram lidos na íntegra, dos quais foram excluídos outros 8 trabalhos por não corresponderem à área temática, resultando em 6 artigos para extração de dados e síntese qualitativa. 
Figura 1. Fluxograma da inclusão dos estudos.

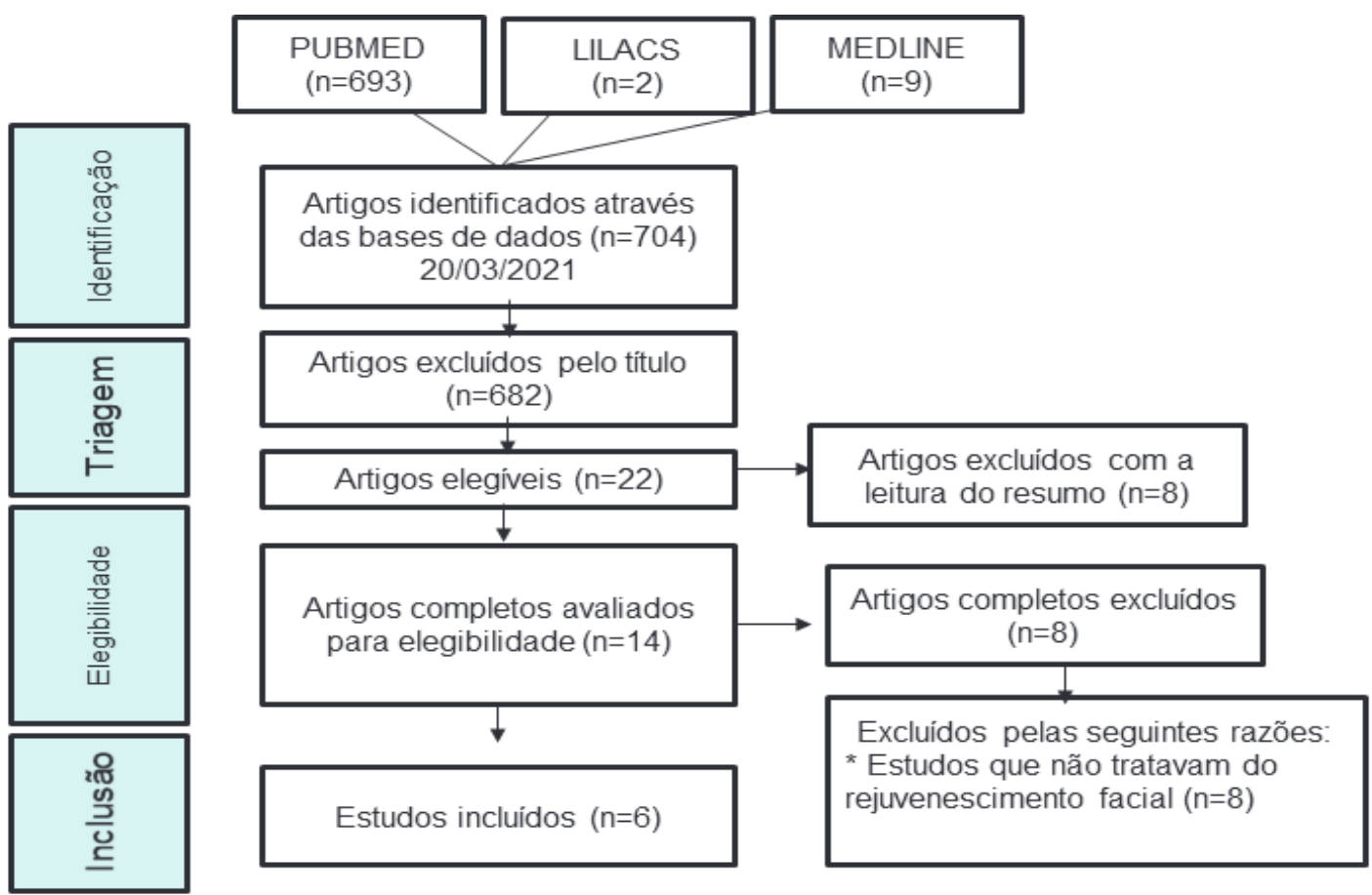

Fonte: Elaborado pela autora.

Dentre os trabalhos que avaliaram o uso do PRF como adjuvante no rejuvenescimento facial (Quadro 2), dois estudos demonstraram melhoria significante de parâmetros da pele ((Liang et al., 2018; Hassan, Quinlan \& Ghanem, 2020), dois estudos não informaram sobre os valores de significância $(\mathrm{P}<0,05)$ (Nacopoulos \& Vesala, 2020; Karimi \& Rockwell, 2019), e dois estudos não observaram mudanças significativas em nenhum dos parâmetros de pele avaliados (Wei et al., 2017; Hu, BassiriTehrani \& Abraham, 2020). Em todos os estudos o uso do material apresentou-se tolerável e não ocasionou efeitos adversos graves. 
Quadro 2. Dados das publicações e considerações sobre os estudos.

\begin{tabular}{|c|c|c|c|c|}
\hline Título & Autor/ Ano & $\begin{array}{l}\text { Delineamento } \\
\text { / Amostra }\end{array}$ & Objetivos & Desfecho \\
\hline $\begin{array}{l}\text { Lower facial } \\
\text { regeneration with a } \\
\text { combination of } \\
\text { platelet-rich fibrin } \\
\text { liquid matrices } \\
\text { based on the low } \\
\text { speed centrifugation } \\
\text { concept-Cleopatra } \\
\text { technique }\end{array}$ & $\begin{array}{l}\text { Nacapoulos } \\
\& \text { Vesala, } \\
2020\end{array}$ & $\begin{array}{l}\text { Ensaio Clínico } \\
\text { Controlado/ } \\
\mathrm{N}=32\end{array}$ & 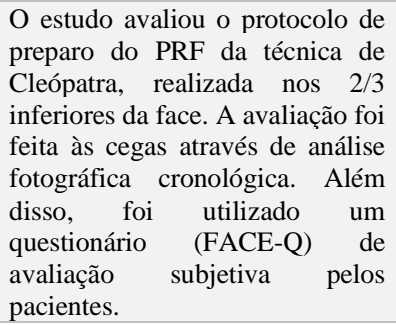 & $\begin{array}{l}\text { Ao final do estudo, mudanças positivas } \\
\text { foram percebidas pelos avaliadores na } \\
\text { diferença cronológica do aspecto da pele. } \\
\text { Alguns efeitos adversos foram relatados } \\
\text { sem graves complicações, concluindo } \\
\text { que a "Técnica de Cléopatra" é efetiva e } \\
\text { bem tolerada. }\end{array}$ \\
\hline $\begin{array}{l}\text { Nanofat-derived } \\
\text { stem cells with } \\
\text { platelet-rich fibrin } \\
\text { improve facial } \\
\text { contour remodeling } \\
\text { and skin } \\
\text { rejuvenation after } \\
\text { autologous } \\
\text { structural fat } \\
\text { transplantation }\end{array}$ & $\begin{array}{l}\text { Wei et al., } \\
2017\end{array}$ & $\begin{array}{l}\text { Ensaio Clínico } \\
\text { Controlado } \\
\text { Randomizado/ } \\
\mathrm{N}=62\end{array}$ & $\begin{array}{l}\text { No estudo, foram avaliados dois } \\
\text { grupos sobre a ação de células } \\
\text { tronco derivadas de nanogorduras } \\
\text { (NFSCs) em pacientes com sinais } \\
\text { de envelhecimento, um recebeu } \\
\text { NFSC junto do PRF (Grupo de } \\
\text { tratamento) e o outro só NFSC } \\
\text { sem PRF (Grupo controle), o } \\
\text { resultado foi avaliado pelos } \\
\text { aparelhos VISIA® e SOFT®. }\end{array}$ & $\begin{array}{l}\text { Aumento de proliferação e diferenciação } \\
\text { adipogênica dos NFSCs (in vitro) e } \\
\text { melhora da textura, elasticidade, tamanho } \\
\text { dos poros, rugas e hidratação da pele (in } \\
\text { vivo) nos dois grupos, com maior } \\
\text { satisfação no grupo que utilizou PRF } \\
\text { associado. }\end{array}$ \\
\hline $\begin{array}{l}\text { Precise Intradermal } \\
\text { Injection of Nanofat } \\
\text { Derived Stromal } \\
\text { Cells Combined } \\
\text { with Platelet-Rich } \\
\text { Fibrin Improves the } \\
\text { Efficacy of Facial } \\
\text { Skin Rejuvenation }\end{array}$ & $\begin{array}{l}\text { Liang et al., } \\
2018\end{array}$ & $\begin{array}{l}\text { Ensaio Clínico } \\
\text { Controlado/ } \\
\mathrm{N}=103\end{array}$ & $\begin{array}{l}\text { Um grupo com sinais de } \\
\text { envelhecimento da face recebeu } \\
\text { aplicação de células-tronco } \\
\text { derivadas de nanogorduras } \\
\text { (NFSCs) associadas ao PRF, } \\
\text { enquanto o grupo controle foi } \\
\text { submetido a tratamento com HA. } \\
\text { Os resultados foram obtidos } \\
\text { através de análise fotográfica e } \\
\text { pelos instrumentos VISIA® e o } \\
\text { SOFT® } 5.5 \text {. }\end{array}$ & $\begin{array}{l}\text { A aplicação de NFSC-PRF demonstrou } \\
\text { excelente proliferação, diferenciação e } \\
\text { função parácrina quando comparados ao } \\
\text { HA, tendo as duas apresentado melhorias } \\
\text { da pele, embora uma maior taxa de } \\
\text { satisfação dos pacientes foi obtida no } \\
\text { grupo de tratamento. }\end{array}$ \\
\hline $\begin{array}{l}\text { The Benefits of } \\
\text { Platelet Rich Fibrin }\end{array}$ & $\begin{array}{l}\text { Karimi K et } \\
\text { al., } 2019\end{array}$ & $\begin{array}{l}\text { Estudo } \\
\text { Prospectivo/ } \\
\mathbf{N = 3}\end{array}$ & $\begin{array}{l}\text { Esse estudo compara o PRF com } \\
\text { o PRP e, demonstra seus } \\
\text { benefícios em terapias em que o } \\
\text { PRF é combinado ao HA e } \\
\text { aplicado na face sendo avaliado } \\
\text { através da análise fotográfica } \\
\text { cronológica. }\end{array}$ & $\begin{array}{l}\text { O autor concluiu que } \mathrm{O} \text { PRF e o HA } \\
\text { quando unidos, oferecem um melhor } \\
\text { suporte para o crescimento do colágeno, } \\
\text { levando a um efeito preenchedor } \\
\text { duradouro tendo como suporte as } \\
\text { vantagens do PRF. }\end{array}$ \\
\hline $\begin{array}{l}\text { Injectable platelet- } \\
\text { rich fibrin for facial } \\
\text { rejuvenation: A } \\
\text { prospective, single- } \\
\text { center study }\end{array}$ & $\begin{array}{l}\text { Hassan et al., } \\
2020\end{array}$ & $\begin{array}{l}\text { Estudo } \\
\text { Prospectivo } \\
\text { Unicêntrico/ } \\
\mathrm{N}=11\end{array}$ & $\begin{array}{l}\text { Este estudo avaliou a eficácia do } \\
\text { I-PRF no rejuvenescimento facial } \\
\text { usando um sistema de análise de } \\
\text { pele objetivo (VISIA } ® \text { ) e } \\
\text { medidas validadas de resultados } \\
\text { relatados pelo paciente (FACE- } \\
\text { Q). }\end{array}$ & $\begin{array}{l}\text { Foi encontrado melhora significativa } \\
\text { relacionada a superfície da pele e poros, } \\
\text { através da injeção do i-PRF e a promoção } \\
\text { de significante rejuvenescimento da face } \\
\text { após } 3 \text { meses. }\end{array}$ \\
\hline $\begin{array}{l}\text { The Effect of } \\
\text { Platelet-Rich Fibrin } \\
\text { Matrix on Skin } \\
\text { Rejuvenation: A } \\
\text { Split-Face } \\
\text { Comparison }\end{array}$ & $\begin{array}{l}\text { Hu et al., } \\
2020\end{array}$ & $\begin{array}{l}\text { Ensaio Clínico } \\
\text { Duplo-cego } \\
\text { controlado por } \\
\text { placebo } \\
\text { Split-face/ } \\
\mathrm{N}=30\end{array}$ & $\begin{array}{l}\text { Um grupo recebeu aplicação de } \\
\text { PRFM (tratamento) em uma } \\
\text { hemiface e a aplicação de soro } \\
\text { fisiológico (NFL) na outra } \\
\text { hemiface, observando alterações } \\
\text { ocorridas nos dois lados de acordo } \\
\text { com os parâmetros do aparelho } \\
\text { VISIA®. }\end{array}$ & $\begin{array}{l}\text { O único parâmetro de pele onde houve } \\
\text { melhora foi a qualidade da textura da pele } \\
\text { na presença do PRFM. Não houve } \\
\text { significância estatística na mudança de } \\
\text { escore para qualquer um dos parâmetros } \\
\text { individuais da pele. Os resultados } \\
\text { parecem persistir por pelo menos } 6 \\
\text { semanas. }\end{array}$ \\
\hline
\end{tabular}

Fonte: Autores.

Na síntese qualitativa dos 6 estudos incluídos nessa revisão, foi verificado que haviam 2 ensaios clínicos controlados, 1 ensaio clínico controlado com face dividida (split-face), 1 ensaio clínico randomizado (ECR), e 2 estudos prospectivos. Os trabalhos incluídos apresentavam as seguintes comparações: injeção intradérmica de PRF + HA (antes x depois), injeção intradérmica de i-PRF + PRFM (antes x depois), injeção intradérmica de i-PRF (antes x depois), Injeção intradérmica de NFSCPRF x HA, Injeção intradérmica de PRFM (hemiface) x soro fisiológico (hemiface), Injeção intradérmica de NFSCs-PRF x NFSCs sem PRF, nos quais a principal expectativa era diminuir rugas, flacidez e manchas pigmentares (Nacopoulos \& Vesala, 2020; Karimi \& Rockwell, 2019).

A idade dos voluntários das amostras foi em média de 42.2 anos (variando entre 30 e 60 anos) e a principal queixa entre 
eles era a presença de sinais de envelhecimento cutâneo. Os estudos duraram em média 15 meses, variando entre uma e três sessões de aplicação (Quadro 3) e, entre as doses de 0,5-16,5mL, a depender da área e do número de pontos de aplicação recomendado, tendo como técnica empregada a injeção intradérmica de PRF puro ou combinado com outro material autólogo ou sintético, não havendo padronização quanto ao seu preparo.

Quadro 3. Protocolos de aplicação do PRF.

\begin{tabular}{|c|c|c|c|c|c|}
\hline Autores/ Periódico & País & Método/ Dose & $\begin{array}{l}\text { Sessões/ } \\
\text { Intervalo }\end{array}$ & Seguimento & $\begin{array}{c}\text { Centrifugação / } \\
\text { Preparo }\end{array}$ \\
\hline $\begin{array}{l}\text { Nacapoulos \& } \\
\text { Vesala } \\
\text { J Cosmet Dermatol }\end{array}$ & Grécia & $\begin{array}{l}\text { Injeção } \\
\text { intradérmica/ } \\
2-3 \mathrm{~mL}\end{array}$ & $\begin{array}{c}3 \text { sessões } \\
\text { com intervalo } \\
\text { de } 2-3 \\
\text { semanas }\end{array}$ & 12 semanas & $\begin{array}{c}\text { Única/ } \\
\text { 3-4,5ml Protocolo de } \\
\text { baixo RCF } \\
+ \\
\text { 7,5-9mL Protocolo de } \\
\text { alto RCF }\end{array}$ \\
\hline $\begin{array}{l}\text { Wei et al. } \\
\text { Oncotarget }\end{array}$ & China & $\begin{array}{l}\text { Injeção } \\
\text { intradérmica/ } \\
2-16,5 \mathrm{~mL}\end{array}$ & Sessão única & $12-24$ meses & $\begin{array}{c}\text { Única/ } \\
\text { NFSC com PRF } \\
\text { (Grupo de tratamento) } \\
\text { NFSC sem PRF (Grupo } \\
\text { controle) }\end{array}$ \\
\hline $\begin{array}{l}\text { Liang et al. } \\
\text { Cell Physiol } \\
\text { Biochem }\end{array}$ & China & $\begin{array}{l}\text { Injeção } \\
\text { intradérmica/ } \\
4-5 \mathrm{~mL}\end{array}$ & Sessão única & 24 meses & $\begin{array}{c}\text { Única/ } \\
\text { NFSC-PRF } \\
\text { (Grupo de tratamento) } \\
\text { HA } \\
\text { (Grupo controle) }\end{array}$ \\
\hline $\begin{array}{l}\text { Karimi K, et al. } \\
\text { Facial Plast Surg } \\
\text { Clin North }\end{array}$ & USA & $\begin{array}{c}\text { Injeção } \\
\text { intradérmica/ } \\
\text { NI }\end{array}$ & $\begin{array}{c}3 \text { sessões } \\
\text { com intervalo } \\
\text { de } 4-6 \\
\text { semanas }\end{array}$ & 3-5 meses & $\begin{array}{c}\text { Única/ } \\
2 \text { partes de HA } \\
+ \\
1 \text { parte de PRF }\end{array}$ \\
\hline $\begin{array}{l}\text { Hassan et al. } \\
\text { J Cosmet Dermatol }\end{array}$ & UK & $\begin{array}{c}\text { Injeção } \\
\text { intradérmica/ } \\
0,5-1 \mathrm{~mL}\end{array}$ & $\begin{array}{c}3 \text { sessões } \\
\text { com intervalo } \\
\text { de } 4 \text { semanas }\end{array}$ & 3 meses & $\begin{array}{c}\text { Única/ } \\
\text { 4mL de i-PRF (4 } \\
\text { seringas de } 1 \mathrm{~mL} / \text { cada) }\end{array}$ \\
\hline $\begin{array}{l}\text { Hu et al. } \\
\text { The Aesthetic } \\
\text { Society }\end{array}$ & USA & $\begin{array}{l}\text { Injeção } \\
\text { intradérmica/ } \\
2-4 \mathrm{~mL}\end{array}$ & $\begin{array}{c}3 \text { sessões } \\
\text { com intervalo } \\
\text { de } 4-6 \\
\text { semanas }\end{array}$ & 12 semanas & $\begin{array}{c}\text { Única/ } \\
\text { PRFM (Tratamento) } \\
\text { em hemiface e } \\
\text { Soro fisiológico } \\
\text { (Placebo) na outra } \\
\text { hemiface. }\end{array}$ \\
\hline
\end{tabular}

NI = Não informado. Fonte: Autores.

Apesar de haverem algumas contraindicações (Quadro 4), o PRF tem sido considerado um material seguro pelos autores que o utilizaram, proporcionando uma recuperação mais regular e apresentado menos reações adversas, além de demostrar resultado superior, quanto comparado a outros materiais injetáveis sintéticos (Lin \& Sclafani, 2018; Storrer et al., 2019; Karimi \& Rockwell, 2019). 
Quadro 4. Contraindicações de saúde ao uso de PRF.

\begin{tabular}{|l|l|}
\hline \multicolumn{2}{|c|}{ Desordens e condições de saúde } \\
\hline Anemia severa ou desordens sanguíneas & Gestação ou lactação \\
\hline História de imunossupressão & Uso de drogas corticóides ou citotóxicas \\
\hline Distúrbios da pele e/ou conjuntivo & Tratamento de radioterapia \\
\hline Anafilaxias ou história de reação alérgica grave & Distúrbios crônicos como câncer e falência renal \\
\hline
\end{tabular}

Fonte: Adaptado de Liang et al. (2018); Nacapoulos e Vesala (2019).

Não foi recomendado realizar procedimentos estéticos em pacientes grávidas ou lactentes com histórico de anemia ou condições sanguíneas, alergias graves, distúrbios da pele e/ou do tecido conjuntivo, história de imunossupressão, ou que façam uso contínuo de droga citotóxica ou corticosteróide (Anitua, 1999; Choukroun, Adda, Schoeffler \& Vervelle, 2001), cabendo ao cirurgião-dentista a investigação dessas condições durante a anamnese e, estando sua responsabilidade orientar e buscar a avaliação médica em casos que exista algum risco (Nacopoulos \& Vesala, 2020; Liang et al., 2018).

\section{Discussão}

A avaliação dos artigos sugeriu que a melhoria do aspecto cutâneo após o emprego de PRF na face é tangível, e, segundo os autores, ocorreu melhora significante de um ou mais aspectos da pele (manchas pigmentares, porfirinas, poros, rugas, flacidez) após os tratamentos. De acordo com apenas dois autores (Liang et al., 2018; Hassan, Quinlan \& Ghanem, 2020), houve melhoria significante $(\mathrm{P}<0,05)$ em parâmetros de pele conhecidos, de acordo com o método de análise objetiva VISIA®.

Foi notado que, dentre os periódicos que publicaram os trabalhos incluídos nessa síntese qualitativa, os estudos são, em sua maioria, originais de revistas médicas da área de dermatologia e cirurgia plástica, e não de revistas de relevância para a área odontológica.

A maioria dos autores concordou que não houve relação entre o PRF e a produção de efeitos adversos graves como infecção, anafilaxia ou parestesia, no entanto, foram explicitados apenas no estudo de Nacapoulos e Vesala alguns casos de dor de cabeça de intensidade média, vermelhidão e edema no pós-procedimento, tendo breve resolução e sendo tratados com analgésico (dipirona por via oral) e gelo nas regiões de queixa, sem maiores complicações.

Os estudos que associaram o PRF a células-tronco derivadas de nanogorduras (NFSCs) e ao ácido hialurônico (HA) destacaram que seu uso reduziu a reabsorção dos enxertos de gordura e otimizou o efeito preenchedor do ácido hialurônico e melhorou textura e manchas na pele (Wei et al., 2017; Liang et al., 2018; Karimi \& Rockwell, 2019), visto que, devido a suas propriedades, ele possui liberação prolongada de fatores de crescimento pela matriz de fibrina autóloga, ampliando as vantagens dos materiais injetados com fim rejuvenescedor.

A técnica de preparo variou entre os autores, não havendo evidência científica de eficácia advinda de um protocolo padrão de preparo do PRF ou de qualquer outro concentrado sanguíneo (Storrer et al., 2019), tendo como base para escolha do protocolo as necessidades e expectativas individuais do paciente (Nacopoulos \& Vesala, 2020; Wei et al., 2017; Liang et al., 2018).

Durante esse estudo notou-se que existem poucos ensaios clínicos randomizados e/ou estudos cegos que avaliaram o uso de PRF com fim rejuvenescedor na face, portanto, são necessários novos estudos que avaliem melhor seus efeitos na remodelação dos tecidos da pele da face a longo prazo. 


\section{Conclusão}

Concluiu-se através dessa revisão integrativa que o PRF é um material seguro e proporciona uma melhora relacionada a textura, poros e marcas na pele, quando usado isoladamente ou combinado com algum outro tipo de material sob as condições informadas, havendo evidências insuficientes de que ele é eficaz sob outras circunstâncias. Os estudos sugeriram que a aplicação de PRF tem efeitos benéficos, sendo a utilização da fibrina rica em plaquetas uma opção válida em terapias estéticas na área odontológica.

Vale ressaltar que o PRF é uma técnica nova de tratamento e que seu resultado em longo prazo ainda é desconhecido, fazendo-se necessário a realização de novos ensaios clínicos randomizados robustos sobre o uso desse material no rejuvenescimento facial.

\section{Referências}

Anitua, E. (1999). Plasma rich in growth factors: preliminary results of use in the preparation of future sites for implants. Int J Oral Maxillofac Implants. 14, 529-535.

Bielecki, T., \& Dohan Ehrenfest, D. M. (2012). Platelet-rich plasma (PRP) and Platelet-Rich Fibrin (PRF): surgical adjuvants, preparations for in situ regenerative medicine and tools for tissue engineering. Curr Pharm Biotechnol. 13(7), 1121-1130.

Choukroun, J., Adda, F., Schoeffler, C. \& Vervelle, A. (2001). Une opportunité en paro-implantologie: Le PRF. Implantodontie. 42, 55-62.

Choukroun, J. (2017). Platelet Rich Fibrin in regenerative dentistry: biological background and clinical indications. Wiley-Blackwell. 355-406.

Conselho Federal de Odontologia (2015). Resolução CFO No 158, de 8 de junho de 2015. Regulamenta o uso de Agregados Plaquetários Autólogos para fins não transfusionais no âmbito da Odontologia. Diário Oficial União.

Dohan Ehrenfest, D. M., Del Corso, M., Diss, A., Mouhyi, J. \& Charrier, J. B. (2010). Three-dimensional architecture and cell composition of a Choukroun's platelet-rich fibrin clot and membrane. J Periodontol. 81(4), 546-55.

El Bagdadi, K., Kubesch, A., Yu, X., Al-Maawi, S., Orlowska, A., Dias, A. et al. (2017). Reduction of relative centrifugal forces increases growth factor release within solid platelet-rich-fibrin (PRF)-based matrices: a proof of concept of LSCC (low speed centrifugation concept). Eur J Trauma Emerg Surg.

Gentile, R. D. (2020). Easy Platelet-Rich Fibrin (Injectable/Topical) for Post-resurfacing and Microneedle Therapy. Facial Plast Surg Clin North Am. 28(1), $127-134$.

Hassan, H., Quinlan, D. J. \& Ghanem, A. (2020). Injectable platelet-rich fibrin for facial rejuvenation: A prospective, single-center study. J Cosmet Dermatol. 19(12), 3213-3221.

Hu, S., Bassiri-Tehrani, M. \& Abraham, M. T. (2020). The Effect of Platelet-Rich Fibrin Matrix on Skin Rejuvenation: A Split-Face Comparison. Aesthet Surg J. 20, 244.

Karimi, K., \& Rockwell, H. (2019). The Benefits of Platelet-Rich Fibrin. Facial Plast Surg Clin N Am. 27(1), 331-340.

Kubesch, A., Barbeck, M., Al-Maawi, S., Orlowska, A., Booms, P. F., Sader, R. A., Miron, R. J., Kirkpatrick, C. J., Choukroun, J. \& Ghanaati, S. (2019). Um conceito de centrifugação de baixa velocidade leva ao acúmulo celular e vascularização de fibrina sólida rica em plaquetas: um estudo experimental in vivo. Platelets. 30(3), 329-340.

Liang, Z. J., Lu, X., Li, D. Q., Liang, Y. D., Zhu, D. D., Wu, F. X., Yi, X. L., He, N., Huang, Y. Q., Tang, C. \& Li, H. M. (2018). Precise Intradermal Injection of Nanofat-Derived Stromal Cells Combined with Platelet-Rich Fibrin Improves the Efficacy of Facial Skin Rejuvenation. Cell Physiol Biochem. 47(1):316329.

Lin, J. \& Sclafani, A. P. (2018). Platelet-Rich Plasma for Skin Rejuvenation and Tissue Fill. Facial Plast Surg Clin North Am. 26(4), 439-446.

Marx, R. E., Carlson, E. R., Eichstaedt, R. M., Schimmele, S. R., Strauss, J. E. \& Georgeff, K. R. (1998). Platelet-rich plasma: Growth factor enhancement for bone grafts. Oral Surg Oral Med Oral Pathol Oral Radiol Endod. 85, 638-646.

Mihaylova, Z., Mitev, V., Stanimirov, P., Isaeva, A., Gateva, N., Ishkitiev, N. et al. (2017). Use of platelet concentrates in oral and maxillofacial surgery: An overview. Acta Odontol Scand. 75, 1-1.

Nacopoulos, C. \& Vesala, A. M. (2020). Lower facial regeneration with a combination of platelet-rich fibrin liquid matrices based on the low speed centrifugation concept-Cleopatra technique. J Cosmet Dermatol. 19(1), 185-189.

Nurden, A. T., Nurden, P., Sanchez, M., Andia, I. \& Anitua, E. (2008). Plaquetas e cicatrização de feridas. Frente Biosci. 13, 3532-3548. 18508453.

Shahram Ghanaati, Patrick Booms, Anna Orlowska, Alica Kubesch, Jonas Lorenz, Jim Rutkowski, Constantin Landes, Robert Sader, CJ Kirkpatrick \& Joseph Choukroun (2014). Advanced Platelet-Rich Fibrin: A New Concept for Cell-Based Tissue Engineering by Means of Inflammatory Cells. J Oral Implantol. 40(6), 679-689. 
Research, Society and Development, v. 10, n. 9, e19610917676, 2021

(CC BY 4.0) | ISSN 2525-3409 | DOI: http://dx.doi.org/10.33448/rsd-v10i9.17676

Simonpieri. A., Del Corso, M., Vervelle, A., Jimbo, R., Inchingolo, F. \& Sammartino, G. et al. (2012). Current knowledge and perspectives for the use of plateletrich plasma (PRP) and platelet-rich fibrin (PRF) in oral and maxillofacial surgery part 2: bone graft, implant and reconstructive surgery. Curr Pharm Biotechnol. 13(7), 1231-1256.

Souza, M. T., Silva, M. D., \& Carvalho, R. (2010). Revisão integrativa: o que é e como fazer. Rev Einstein, 8(1), $102-6$.

Storrer, C. L. M., Andrade, C. F., Chaves, L. H. K., Wambier, L. M., De-Geus, J. L. \& Zielak J. C. (2019). Injeção de agregados plaquetários no rejuvenescimento facial: uma revisão sistemática. Rev. Bras. Cir. Plást. 34(2), 274-282.

Wang, X., Zhang, Y., Choukroun, J., Ghanaati, S. \& Miron, R. J. (2017). Effects of an injectable platelet-rich fibrin on osteoblast behavior and bone tissue formation in comparison to platelet-rich plasma. Platelets. $29,1-8$.

Wei, H., Gu, S. X., Liang, Y. D., Liang, Z. J., Chen, H., Zhu, M. G., Xu, F. T., He, N., Wei, X. J. \& Li, H. M. (2017). Nanofat-derived stem cells with plateletrich fibrin improve facial contour remodeling and skin rejuvenation after autologous structural fat transplantation. Oncotarget. 8(40), 68542-68556.

Whitmann, D. H., Berry, R. L. \& Green, D. M. (1997). Platelet gel: an alternative to fibrin glue with applications in oral and maxillofacial surgery. J Oral Maxillofac Surg. 55, 1294-1299. 